\title{
Endoscopic Treatment of a Gastric Dieulafoy's Lesion
}

\author{
Sinkeet Simeon Ranketi ${ }^{1}$, Stephen Louis Burgert ${ }^{1}$, Robert Parker ${ }^{2}$ \\ 1. Tenwek Hospital, Bomet \\ 2. Warren Alpert School of Medicine, Brown University
}

Correspondence to: Dr.Sinkeet Ranketi, P.0 Box 39, 20400 Bomet, Kenya. Email: komoisi@yahoo.com

\section{Summary}

Gastrointestinal (GI) bleeding is associated with significant mortality and a prompt search and treatment of the etiology is important. Upper GI endoscopy is the gold standard for diagnosis and treatment after initial resuscitation of the patient. In a majority of cases, the cause will be easily identified during endoscopy. Dieulafoy's lesion, a caliber persistent artery in the submucosa, is a rare but important cause of intermittent painless massive GI bleeding. Due to its intermittent nature, it can easily be missed and often requires multiple endoscopic evaluations. We present a case of one such patient with subsequent endoscopic findings and successful treatment along with a review of the literature.

Keywords: Endoscopy; Hematemesis; Dieulafoy's lesion; Stomach

Ann Afr Surg. 2016;13(2): 86-9.

DOI: http://dx.doi.org/10.4314/aas.v13i2.13

\section{Introduction}

Upper gastrointestinal (GI) bleeding is a medical emergency that warrants prompt identification of cause and appropriate treatment. Although etiologies differ with the age of the patient, nature of the bleed, and preceding history; the majority of causes of upper GI bleeding can be attributed to sequela of peptic ulcer disease, variceal disease, and malignancy. Endoscopy remains the gold standard for the diagnosis and treatment of upper GI bleeding. In a majority of cases, the apparent cause of the bleed is easily identified during the endoscopic evaluation. However, at times, patients can present as diagnostic enigmas with repeat negative endoscopy findings despite evidence of repeated episodes of hematemesis, melena, or a dropping hematocrit.

\section{Case report}

A 74-year-old woman, with controlled hypertension and diabetes, was referred to the endoscopy unit at Tenwek Hospital with a history of five episodes of vomiting frank blood. The initial episode was reported to have been approximately $150 \mathrm{~mL}$ and subsequent ones were approximately 75 to $100 \mathrm{~mL}$ each. She described general body weakness but denied any preceding vomiting or abdominal pain. She denied any prior history of vomiting blood, early satiety, or change in stool color prior to the first episode. She also denied any previous use of alcohol or report of liver disease. Her medications were atenolol, nifedipine, losartan, metformin, and mixtard insulin. She denied using aspirin, clopidogrel, or any nonsteroidal anti-inflammatory drugs (NSAIDS). On presentation, she was breathing with ease, appeared pale and had no stigmata of liver disease. Her blood pressure was $143 / 59 \mathrm{mmHg}$, temperature $36.7^{\circ} \mathrm{C}$ and pulse rate 80 beats per minute. Her abdomen was slightly distended, soft and with no organomegally. Her hemoglobin level was $11.9 \mathrm{~g} / \mathrm{dl}$, platelets count of 167,000 , international nationalized ratio (INR) of 1.28 , sodium $137 \mathrm{mmol} / \mathrm{L}$ and elevated potassium $5.6 \mathrm{mmol} / \mathrm{L}$.

The patient was resuscitated with two litres of normal saline and intravenous omeprazole $40 \mathrm{mg}$ at the 
emergency department. Patient was prepared for an emergent endoscopy which revealed a small vascular bleb on the greater curvature of the gastric body at $49 \mathrm{~cm}$ from upper incisors. Although the lesion was not actively bleeding, it was identified as the apparent cause of bleeding. No surrounding inflammation and no blood in the stomach was found. The area was marked with a tattoo for easy identification in case of rebleeding. The rest of the stomach had mild diffuse erythema. The esophagus and duodenum up to its third portion were all grossly normal. The patient was started empirically on Helicobacter pylori kit for 14 days and planned to undergo repeat hemoglobin checks after 1 and 4 weeks. She was also advised to avoid use of NSAIDs.

Ten days later, the patient had another episode of vomiting fresh blood of reported approximately $500 \mathrm{~mL}$ and her hemoglobin dropped to $8.0 \mathrm{~g} / \mathrm{dL}$. She underwent repeat endoscopy which revealed the small vascular bleb on greater curvature of gastric body at $49 \mathrm{~cm}$ which was not actively bleeding but had an adherent clot (Figure 1a). Three hemostatic Resolution Clips $\AA$ were placed successfully without any complications (Figure 1b \& c). She experienced no further episodes of hematemesis nor were meleanotic stools reported.
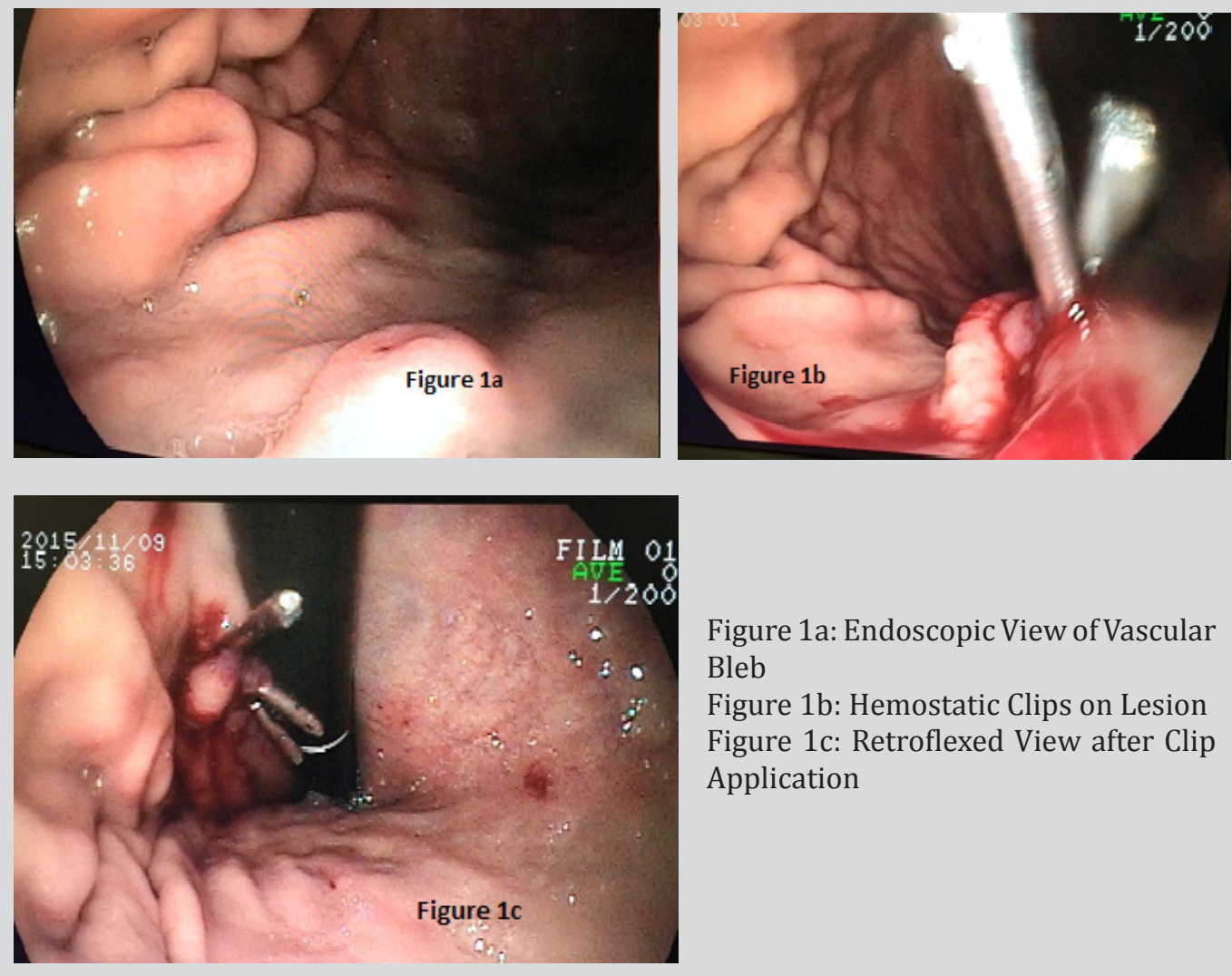

Figure 1a: Endoscopic View of Vascular Bleb

Figure 1b: Hemostatic Clips on Lesion Figure 1c: Retroflexed View after Clip Application

\section{Discussion}

Dieulafoy's lesions, exulceratio simplex, are a rare but challenging cause of upper GI bleeding due to their intermittent nature. Upper GI bleeding carries a significant mortality depending on the etiology and the patient's co-morbid conditions. Dieulafoy's lesions contribute approximately $6 \%$ of non-variceal upper GI bleeds and 1-2\% of all GI bleeding (1-5). These lesions, though first described by Gallard in 1884, have been attributed to Dieulafoy - a French surgeon who described three cases in 1898 (6). These are aberrant large, tortuous, submucosal vessels that can erode through and cause massive, painless and intermittent GI bleeding $(7,8)$. Histologically, the lesions are thick walled large caliber-persistent artery in the submucosa with subintimal fibrosis without surrounding inflammation but can be ulcerated $(3,9)$. The large submucosal vessel pulsations together with mechanical or chemical injury result in erosion of the overlying mucosa and resultant hemorrhage from the vessel. There is still controversy regarding if this is a congenital or acquired age related defect.

Dieulafoy's lesions can occur in patients of any age, with a slight male predominance and no familial tendency. They have been reported in almost every part of the gastrointestinal tract. The majority have 
been reported in the lesser curvature of the stomach where $80-95 \%$ are located approximately $6 \mathrm{~cm}$ distal to the gastro-esophageal junction with blood flow directly from the left gastric artery $(4,10,11)$. Other locations in the GI tract where they have also been reported include the duodenum, colon, jejunum and ileum, rectum and anal canal $(10,12-14)$. Lesions outside of the gastrointestinal tract have also been reported in the bronchus, which can present with episodes of massive hemoptysis and are discovered on bronchoscopy (15). Mortality rate from Dieulafoy's lesions range is variable and is due to massive bleeding with different studies reporting rates as high as $35 \%$ but with advancement and more access to endoscopy, mortality has been reducing with a rate of $8.6 \%$ compared to historical mortality rates of $80 \%(16,17)$. Dieulafoy's lesions typically have an intermittent nature of bleeding and on average, its takes three or more upper GI endoscopies to diagnose (4). Occasionally one would find a spurting arterial bleeder during repeat evaluation or more frequently a nonbleeding vascular bleb with or without an adherent clot. However, due to the lesion's previously mentioned intermittent nature of bleeding, initial endoscopy can be non-revealing and only after repeat careful evaluations would the apparent cause be identified. Another challenge in the identification can also be due to the massive amount of blood in the stomach obscuring it. In the medical literature, patients with bleeding Dieulafoy's lesions would frequently return after an apparently normal endoscopy with another bout of hematemesis in a median duration of 4 days from the initial evaluation (3).

TreatmentofDieulafoy'slesionsdependsonthelocation of the lesion. Historically, surgery was the cornerstone of arresting all bleeding Dieulafoy's lesions. Currently, endoscopy is the gold standard for the treatment of gastric lesions with low reported recurrence rates of less than $10 \%(18,19)$. Several endoscopic techniques are currently instituted including injection of vasoconstrictors like epinephrine, application of hemostatic clips, and banding. The choice of the modality used depends on their availability and the endoscopist's skills and preference. Use of more than one modality in the treatment has been shown to have a lesser risk of recurrence when compared with monotherapy of either of the modalities (20). Mechanical modalities, hemostatic clips and banding, have been proposed to be the initial treatment of choice arguing they would have better control as it results in a smaller lesion compared with injection therapy or thermocoagulation. Small intestine lesions can be diagnosed with capsule endoscopy and surgery is the most common option for treatment, where small bowel enteroscopy is not available.
In the case of our patient, she was not using aspirin, clopidogrel, or any other anticoagulants. She did not have any warning signs in her history to suggest any malignancy and had no signs of liver disease. Our patient had a greater curvature lesion, unlike the typical location in the reported majority in the lesser curvature. Arterial hypertension, which was present in our patient and is a co-morbidity in over $90 \%$ of the patients with bleeding Dieulafoy's lesion, was not found to be a risk factor for re-bleeding in Dieulafoy's lesions $(3,8)$. During the initial endoscopy, no features suggestive of ongoing bleeding and therefore no intervention done then. After the application of the hemostatic clips, the patient did well. At follow-up, she has not had any more episodes of hemorrhage.

\section{Conclusion}

Although uncommon, Dieulafoy's lesions should always be considered as a differential in any patient with massive painless GI bleeding. Due to its intermittent nature, initial evaluation may not identify the lesions thus requiring repeat exams. Endoscopy is the modality of choice for the identification and treatment of gastric Dieulafoy's lesions. A hope of this case presentation and literature review is to encourage providers to remember this potential cause and to facilitate its management when dealing with such dilemmas of chronic anemia, gastrointestinal bleeding, and ongoing hematemesis. This case presentation represents a successfully managed patient whose typical course characterizes the difficulty in identifying Dieulafoy's as the cause of ongoing bleeding.

\section{References}

1. Stark ME, Gostout CJ, Balm R. Clinical Features and Endoscopic Management of Dieulafoy's disease. Gastrointest Endosc. 1992; 38: 545-50.

2. Chaer RA, Helton WS. Dieulafoy's disease. J Am Coll Surg. 2003; 196: 290-6.

3. Chaer RA, Helton WS. Dieulafoy's disease. J Am Coll Surg 2003; 196: 290-296. ***

4. Jamanca-Poma Y, Velasco-Guardado A, Piñero-Pérez C, et al. World J Gastroenterol. 2012;18(40):5734-8

5. Marangoni G, Cresswell AB, Faraj W, Shaikh $\mathrm{H}$, Bowles MJ. An uncommon cause of lifethreatening gastrointestinal bleeding: 2 synchronous Dieulafoy lesions. J Pediatr Surg 2009; 44: 441-443

6. Dieulafoy G. Exulceratio simplex: lecons 1-3. In: Dieulafoy G, editor. Clinique medicale de l'hotel Dieu de Paris. Paris: Masson et Cie; 1898:1-38.

7. Kasapidis P, Georgopoulos P, Delis V, et al. Endoscopic Management and Long-Term Follow- 
Up of Dieulafoy's Lesions in the Upper GI Tract. Gastrointest Endosc. 2002;55:527-31.

8. Parra-Blanco A, Takahashi H, Méndez Jerez PV, et al. Endoscopic Management of Dieulafoy Lesions of the Stomach: A Case Study of 26 patients. Endoscopy. 1997;29:834-9.

9. Juler GL, Labitzke HG, Lamb $\mathrm{R}$, et al. The Pathogenesis of Dieulafoy's Gastric Erosion. Am J Gastroenterol. 1984;79:195-200

10. Scmulewitz N, Baillie J. Dieulafoy Lesions; A Review of 6 Years Experience of a Tertiary Referral Centre. Am J Gastrenterol 2001; 96: 1689-94.

11. Anireddy D, Timberlake G, Seibert D. Dieulafoy's Lesion of the Esophagus. Gastrointest Endosc. 1993; 39: 604.

12. Dulic-Lakovic E, Dulic M, Hubner D, et al. Bleeding Dieulafoy Lesions of the Small Bowel: A Systematic Study on the Epidemiology and Efficacy of Enteroscopic treatment. Gastrointest Endosc. 2011; 74: 573-80

13. Yoshikumi Y, Mashima H, Suzuki J, et al. A Case of Rectal Dieulafoy's Ulcer and Successful Endoscopic Band Ligation. Can J Gastroenterol. 2006; 20: 287-90.

14. Firat O, Karaköse Y, Calişkan C, et al. Dieulafoy's
Lesion of the Anal Canal: Report of a Case. Turk J Gastroenterol. 2007; 18: 265-7.

15. Parrot A, Antoine M, Khalil A, et al. Approach to Diagnosis and Pathological Examination in Bronchial Dieulafoy Disease: A Case Series. Respir Res. 2008; 9:58.

16. Chen JJ, Changchien CS, Lin CC. Dieulafoy's Lesion of the Jejunum. Hepatogastroenterology. 1999;46:1699-701

17. Baxter M, Aly EH. Dieulafoy's Lesion: Current Trends in Diagnosis and Management. Ann R Coll Surg Engl. 2010; 92:548-54.

18. Sone Y, Kumada T, Toyoda H, et al. Endoscopic Management and Follow Up of Dieulafoy Lesion in the Upper Gastrointestinal Tract. Endoscopy. 2005; 37: 449-53.

19. Yamaguchi Y, Yamato T, Katsumi N, et al. Shortterm and Long-Term Benefits of Endoscopic Hemoclip Application for Dieulafoy's Lesion in the Upper GI Tract. Gastrointest Endosc. 2003; 57: 653-56

20. Cui J, Huang LY, Liu YX, et al. Efficacy of Endoscopic Therapy for Gastrointestinal Bleeding from Dieulafoy's Lesion. World J Gastroenterol. 2011; 17: 1368-72. 